\title{
A ATUAÇÃO DO PSICÓLOGO NO CONTEXTO ESCOLAR EM UMA PERSPECTIVA CRÍTICA
}

\author{
Fabiane Salomão Souza', Irineu Aliprando Tuim Viotto Filho² \\ Universidade Estadual Paulista - UNESP, ${ }^{1}$ Mestrado, ${ }^{2}$ Docente. E-Mail: fabiane seduc@presidenteprudente.sp.gov.br, \\ tuimviotto@gmail.com.
}

\section{RESUMO}

O presente artigo faz uma exposição das possibilidades de atuação do psicólogo no contexto escolar baseando-se nos estudos realizados por Patto (1984) em relação ao fenômeno do fracasso escolar, além de outros autores como Souza (2010), Tuleski e Eidt (2007) que analisam as causas dos problemas de aprendizagem não apenas no plano individual, mas como intercorrências de fatores históricos sociais. É realizado um breve resgate histórico da introdução da psicologia na educação e da forma como desenvolveu sua atuação amparada na psiquiatria. São feitas críticas quanto a atuação da psicologia com base positivista e psicométrica que utiliza testes para medir as dificuldades vividas pelos seres humanos. São apontadas possibilidades de intervenção do psicólogo no contexto escolar diante das queixas de problemas de aprendizagem e na inclusão escolar de estudantes com deficiência e dificuldades escolares. Destaca-se a importância da psicologia ao aproximar-se da realidade concreta dos sujeitos, com objetivo de compreendê-los nas suas múltiplas determinações, para não cometer o equívoco de imprimir rótulos, que apenas culpabilizam os sujeitos.

Palavras-chave: Psicologia, Intervenção crítica, Fracasso escolar.

\section{THE PSYCHOLOGIST'S ACTION IN THE SCHOOL CONTEXT IN A CRITICAL PERSPECTIVE}

\begin{abstract}
The present article makes an exposition of the possibilities of performance of the psychologist in the pertaining to school context being based on the studies carried through for Patto (1984) in relation to the phenomenon of the failure pertaining to school, beyond other authors as Souza (2010), Tuleski and Eidt (2007) that they not only analyze the causes of the problems of learning in the individual plan but as intercorrências of social historical factors. A briefing is carried through has rescued historical of the introduction of psychology in the education and the form as it developed its performance supported in psychiatry. They are made critical how much the performance of psychology with positivista and psicométrica base that uses tests to measure the difficulties lived for the human beings. Possibilities of intervention of the psychologist in the pertaining to school context ahead of the complaints of learning difficulty and in the pertaining to school inclusion of students with pertaining to school deficiency and difficulties are pointed. Importance of psychology is distinguished it to to come close itself to the concrete reality of the citizens, with objective to understand them in its multiple determination, not to commit the mistake to print labels, that only culpabilizam the citizens.
\end{abstract}

Keywords : Psychology, pertaining to school critical Intervention, Failure school.

\section{INTRODUÇÃO}

O presente artigo faz uma exposição das possibilidades de atuação do psicólogo no contexto escolar baseando-se nos estudos realizados por Patto (1984) em relação ao fenômeno do fracasso escolar, além de outros autores como Souza (2010), Tuleski e Eidt (2007) que analisam as causas dos problemas de aprendizagem não apenas no plano individual, mas como intercorrências de fatores históricos sociais.

Iniciaremos esta exposição realizando um breve resgate histórico do papel do psicólogo na educação, pois este estudo permite-nos compreender concepções e práticas que ainda encontram-se presentes na escola atual. Segundo 
Patto (1984), a Psicologia nasceu em nosso país a partir da medicina e as primeiras pesquisas feitas em conclusões de cursos nas faculdades de medicina. Para a autora, estas pesquisas baseavam-se em concepções racistas e preconceituosas. Nessa direção, tanto a psiquiatria quanto a psicanálise conquistaram espaço nos estudos sobre doenças mentais e problemas psíquicos e originou-se um movimento que buscava realizar higiene mental nas escolas.

Para a autora, neste período os problemas de aprendizagem e os comportamentais eram explicados por serem conseqüências do "meio", especialmente atribuídos ao ambiente familiar, sem a devida análise histórica e social de tais problemas, fato que possibilitou a culpabilização dos sujeitos em detrimento de uma análise das condições objetivas nas quais os mesmos se encontravam.

Os estudos de Patto (1984) evidenciaram que este movimento cristalizou concepções racistas e biológicas do comportamento humano:

Em outras palavras, foi no fogo cruzado de preconceitos e estereótipos sociais, cientificamente validados, e do ideal liberal da igualdade de oportunidades que se geraram idéias que interferiram nos rumos da política, da pesquisa e das práticas educacionais. (PATTO, 1984, p.113).

A autora ainda destaca que a aplicação de testes de inteligência (Q.I.) em crianças tornou-se prática freqüente com intuito de classificar as turmas e justificar os baixos rendimentos dos alunos e nesse sentido a psicologia de base positivista e psicométrica tomou o principal lugar científico na avaliação das dificuldades vividas pelos seres humanos.

Desta forma, verificamos que foi na avaliação e diagnósticos dos problemas de aprendizagem que a Psicologia entrou no campo educacional, mas com forte influência da medicina, cuja finalidade principal constituia-se em identificar psicopatologias nos indivíduos.

$$
\text { Considerando essa concepção }
$$

psicopatologizante os psicólogos, na sua maioria, centravam na criança os motivos dos problemas escolares, interpretando de forma simplista e reduzida os fenômenos educacionais e desconsiderando as condições históricas e sociais na construção desse processo.

$\mathrm{Na}$ maioria das vezes a avaliação das crianças centrava-se em aspectos imediatos e facilmente identificáveis a partir da observação dos comportamentos dos sujeitos, sem, no entanto, adentrar na identificação das reais determinações das dificuldades vividas na escola. Nesse sentido, há que se pensar necessária e urgentemente na efetivação de uma reflexão crítica sobre os instrumentos padronizados de avaliação psicológica, os quais não podem ser vistos de forma absoluta, mas sim repensados numa perspectiva dialética.

Isto porque, os seres humanos, suas estruturas, características e potencialidades estão em constante movimento e condicionadas às atividades históricas e sociais construídas e efetivadas no seio da própria sociedade, estando diretamente ligadas às condições objetivas de vida de cada ser humano, como afirmam (COLLARES et al. 2012).

Patto (1984), realizando suas reflexões, ainda na década de 80/90, destacou um questionamento importante, que o trazemos para este texto: a serviço de quê e de quem estaria a Psicologia Escolar e a prática psicológica calcada nos princípios positivistas e psicopatologizantes? Em seus estudos a autora ressaltou que a atuação do psicólogo educacional não estava favorecendo a melhora nas relações no interior da escola e ressaltou ainda que a forma como a escola estava organizada, não proporcionava benefícios aos alunos, especialmente, às crianças oriundas das classes mais pobres, principalmente os filhos da classe trabalhadora.

Assim, a história da atuação da Psicologia na educação foi se constituindo, deixando suas marcas e, atualmente, nos deparamos com as conseqüências desta atuação "psicologizante" que consolidou-se no interior das escolas e que, segundo avaliação de Patto (1984) precisa ser superada pois trata-se de uma psicologia ideológica e a serviços da classe dominante.

Verificamos que os estudos de Patto (1984) como também de outros autores expostos neste texto, problematizaram assuntos importantes e possibilitaram mudanças nas concepções de profissionais da educação e da psicologia, mudanças estas que 
levam a psicologia a aproximar-se da realidade concreta dos sujeitos, principalmente das crianças e jovens da escola, principalmente da escola pública, com objetivo de compreendêlos nas suas múltiplas determinações e não simplesmente como resultado do meio ambiente em que vivem e submetidos à uma vida de adaptação na sociedade e na escola.

\section{CONTRADIÇÕES DO CONTEXTO EDUCACIONAL E O PAPEL DO PSICÓLOGO}

Saviani e Duarte (2012) destacam a importância da instituição escolar enquanto espaço específico para a formação do ser humano e, principalmente, para a socialização dos conhecimentos científicos desenvolvidos e acumulados pela humanidade. No entanto, os autores ressaltam que a escola também é um espaço de reprodução das contradições de uma sociedade cujo modelo é o capitalismo, pois o acesso ao conhecimento científico não ocorre da mesma forma e proporção para todas às classes sociais e sim de forma desigual e seletiva.

No geral, os discursos veiculados nos meios de comunicação demarcam que a escola atual é moderna, inclusiva e que atende a todos igualmente, contudo ao verificarmos e analisarmos o grande contingente de alunos que finalizam os estudos do ensino fundamental ciclo II, percebemos, de modo geral, que são poucas as habilidades de leitura e escrita apropriadas pela maioria, não atingindo níveis satisfatórios de aprendizagem, o que nos aponta uma enorme contradição entre o discurso midiático e a realidade constatada nas escolas.

A realidade educacional ainda nos tem mostrado que, freqüentemente, as crianças que apresentam desempenho escolar abaixo da média estão sendo encaminhadas pelas escolas à especialistas como psicólogos, fonoaudiólogos, psicopedagogos, entre outros, com objetivo de serem avaliadas e diagnosticadas em relação a algum 'transtorno' que, talvez, possa estar dificultando sua aprendizagem e desempenho escolar. Tuleski e Eidt (2007), sobre esta problemática, destacam que as avaliações psicoeducacionais realizadas por diversos profissionais transferem problemas sociais ou de ensinagem apenas para o plano individual, ou seja, culpabilizando a criança.

De acordo com Souza (2010), neste contexto cabe ao psicólogo o papel de intervir junto à equipe escolar:
(...) se pautando no compromisso com a luta por uma escola democrática, de qualidade, que garanta os direitos de cidadania a crianças, adolescentes e profissionais que nela atuam. Esse compromisso é político e envolve a construção de uma escola participativa, que possa se apropriar dos conflitos nela existentes e romper com a produção do fracasso escolar. (SOUZA, 2010, pp.143-144).

Sobre o problema das avaliações realizadas por professores e por outros profissionais especializados, cabe ao psicólogo esclarecer com a equipe escolar, que devemos buscar explicações que não se limitem em atribuir as causas das dificuldades apenas a criança, ou que a mesma seja portadora de supostos problemas orgânicos e que para se compreender estes fenômenos torna-se necessário que a equipe escolar reflita de forma crítica, para que possam identificar suas concepções sobre o que esperam do comportamento dos alunos e como entendem o processo de ensino e aprendizagem.

Tuleski e Eidt (2007) ressaltam a importância de focar o processo de escolarização e não os problemas e distúrbios de aprendizagem, na busca de romper com a responsabilização do não-aprender apenas à criança, pois, concordando com as autoras, sabemos que as crianças enfrentam determinadas dificuldades na sua relação com os processos de aprendizagem, situações que surgem do próprio contexto escolar em que estão inseridas e não encontram-se nelas individualmente e tão pouco nas suas condições orgânicas e mentais, como normalmente se apregoa na escola.

Facci (2009) destaca que o psicólogo pode atuar junto aos professores por meio da formação continuada, trabalhando com os conteúdos relacionados ao desenvolvimento e aprendizagem, tendo em vista, oferecer subsídios que possam contribuir para o entendimento de como o aluno aprende. Segundo o Conselho Federal de Psicologia (2013) com esta atuação, 
busca-se contribuir para o aprofundamento teórico para compreender as relações existentes entre a subjetividade humana, a formação do psiquismo e o processo educacional, formados nas relações sociais

Outra possibilidade de intervenção do psicólogo é diante das relações entre família e escola, que ocorrem permeadas por conflitos e tensões. Muitos professores ainda acreditam em modelos idealizados de família, o que os levam muitas vezes, a atribuir as dificuldades apresentadas pela criança unicamente a falta de apoio ou estimulação no ambiente familiar. A atuação do psicólogo com familiares, ou responsáveis, direciona-se no sentido de refletir sobre o papel social da escola e também da própria família na vida da criança.

Sabemos que Frente a algum tipo de dificuldade escolar, todos os envolvidos, escola, família devem discutir em conjunto buscando novas formas e ações de auxiliar a criança almejando a qualidade no processo de ensino e aprendizagem uma vez que todos encontram-se em relação e determinam-se mutuamente.

Com o processo de inclusão escolar houve um aumento significativo no número de alunos matriculados na rede regular de ensino e por isso foram estabelecidas políticas públicas em Educação Especial, com objetivo de garantir direitos e favorecer o desenvolvimento da criança com deficiência.

$\mathrm{Na}$ Política Nacional de Educação Especial são considerados público alvo os estudantes com deficiência, transtornos globais do desenvolvimento e altas habilidades/superdotação Brasil (2013). No entanto, a compreensão do princípio de escola para todos, engloba a inclusão de todas as crianças, independente de raça, religião, condição socioeconômica, desempenho escolar, dentre outras situações de dificuldades pessoal e/ou social.

Frente esta realidade, o psicólogo deve proporcionar discussões entre equipe escolar e familiares, com objetivo de auxiliar no processo de inclusão da criança na escola e estimular sua interação com o grupo de crianças. Diante das diversas demandas que se apresentam com a Educação Especial, a atuação do psicólogo deve ultrapassar a atuação clínica e direcionar-se para o contexto educacional. No entanto, sua atuação se baseará na interdisciplinariedade, ou seja, se complementará com ações intersetoriais, evolvendo educação, saúde, assistência social, universidades e demais segmentos que possam contribuir para a inclusão de crianças público alvo da Educação Especial. A respeito da atuação do psicólogo com estudantes público alvo da educação especial destacamos:

(...) o psicólogo focalizará a força que esse estudante possui para criar condições para o enfrentamento de sua deficiência e expansão de seus limites, que tem como objetivo buscar uma posição social mais valorizada pela sua comunidade. (CONSELHO FEDERAL DE PSICOLOGIA, 2013, p.60).

Cabe ao psicólogo esclarecer a importância da convivência da criança com deficiência em ambientes heterogêneos com objetivo de proporcionar situações instigantes e desafiadoras que possibilitem novas aprendizagens e o desenvolvimento de suas potencialidades.

\section{O PSICÓLOGO ESCOLAR ATUANDO EM UMA PERSPECTIVA CRÍTICA}

Segundo Souza (2009) as críticas à forma como a psicologia desenvolvia seu trabalho, inicialmente realizadas por Patto (1984), levaram os profissionais da área a desenvolverem estudos na direção da transformação das suas práticas profissionais. Estas modificações na prática do psicólogo escolar foram expostas neste artigo, quando descrevemos a história da psicologia na educação e seus desdobramentos na vida dos sujeitos participantes da escola.

Apoiando-nos em estudos realizados sobre este tema, consideramos que para o psicólogo escolar desenvolver uma pratica crítica, torna-se fundamental que ele compreenda os fenômenos que se manifestam na escola como um todo social, não limitando-se ao indivíduo e centrando-se apenas na criança mas sim, analisar os processos de escolarização, como afirma Souza (2009), constituídos pelas dimensões institucional, pedagógica e relacional. Nesse sentido, no interior da escola, a atuação do psicólogo deve desprender-se do enquadramento clínico, da utilização de testes padronizados e voltar-se para as relações que se produzem na escola e as implicações desse 
processo na vida escolar dos indivíduos, no caso, os alunos.

Souza (2009) também destaca que a luta por uma escola realmente democrática, que possibilite a participação de todos, que trabalhe em busca da formação do pensamento científico e crítico em seus estudantes a partir da transmissão dos conhecimentos produzidos pela humanidade, deve ser o foco principal do psicólogo escolar. Continua a autora afirmando que atuar em uma perspectiva histórico-crítica, possibilita ao psicólogo entender o papel da escola na vida dos indivíduos e, simultaneamente, compreender o potencial dessa instituição para transformar as consciências dos sujeitos nela inseridos. Neste sentido, então, enfatizamos a importância de uma atuação crítica na escola, que proporcione a transformação qualitativa dos indivíduos, com vistas à transformação da escola e da sociedade.

Enfim, discutimos neste texto a importância do trabalho da psicologia escolar e do psicólogo na escola e queremos enfatizar a efetivação de uma atuação crítica, pois a psicologia precisa libertar-se de suas origens positivistas e idealistas e, nesse processo de superação, reconhecer os seres humanos como histórica e socialmente determinados.

A necessidade de uma psicologia numa direção crítica e dialética no interior da escola implica que os psicólogos preocupados com a compreensão da realidade concreta do indivíduo na escola devem assumir os pressupostos do materialismo histórico dialético e reconheceram que a necessidade de reconstruir a psicologia nessa direção metodológica ajuda a explicar concretamente a vida das crianças e jovens que vivem dificuldades de aprendizagem e o fracasso escolar e, desta forma, desenvolverem temas e compreensões teóricas e práticas relacionados ao estudo do fenômeno humano para se esboçar possibilidades de construção de uma visão crítica de psicologia e, simultaneamente, de educação.

Tanamachi (1997, p.107) ao discutir a atuação do psicólogo crítico na escola, afirma que é no interior da educação escolar que cada profissional interessado em realizar a aproximação entre a psicologia e a educação deve encontrar o objetivo de sua atuação crítica, uma vez que "o psicólogo escolar deve tomar a educação escolar como objeto de investigação, a serviço do qual colocar-se-á tanto como pesquisador, como aplicando os conhecimentos acumulados pela psicologia".

Podemos compreender, portanto, considerando as reflexões de Tanamachi (1997) que é no interior da educação escolar como um todo e não simplesmente na escola, mas também nela, é claro, que o psicólogo deve atuar, estudando o processo de transmissão e assimilação do conhecimento pelos estudantes e, nesse processo, desvendar as formas como os estudantes aprendem e seu processo de desenvolvimento a partir da apropriação dos conteúdos escolares que os psicólogos, definemse como escolares, psicólogos escolares, sendo que essa postura cabe, certamente, para os demais profissionais da educação ao se intitulares profissionais da educação ou escolares.

\section{CONCLUSÃO}

Sabemos que as escolas vivem dificuldades no que se refere a situação de ensino dos professores, assim como da situação de aprendizagem dos alunos, no entanto, tal situação não é natural mas sim, social e histórica, e desta forma deve ser enfrentada, ou seja, há que se buscar possibilidades de enfrentamento da realidade escolar a partir de uma concepção materialista histórica e dialética, porque capaz de compreender os fenômenos que se apresentam na escola de forma concreta e multideterminada e, desta forma, encaminhar possíveis soluções para as dificuldades encontradas no seu interior.

Enfim, finalizamos nossas reflexões enfatizando a necessidade da psicologia dirigirse à escola e aos educadores da escola de forma crítica e essa visão crítica constitui-se pela apropriação e aplicação dos princípios do método materialista histórico e dialético, sobretudo porque essa possibilidade de compreender a realidade escolar ensina e reconhecer o processo de constituição dos fenômenos escolares, para conhecer suas causas e nelas atuar de forma consciente, fato que implica compreender os estudantes e suas dificuldades, como também o processo de formação dos professores e outros profissionais da educação, sem, no entanto, culpabilizá-los pelo fracasso escolar.

Nesse sentido, a psicologia numa perspectiva crítica, ao chegar à escola, deverá colocar-se ao lado dos professores, assim como dos estudantes, pois o trabalho de superação das dificuldades escolares, tanto dos estudantes 
como dos próprios professores para lidarem com tais dificuldades, passa pelo trabalho coletivo e compartilhado em que todos os profissionais voltam-se para compreender a realidade da escola nas suas múltiplas determinações, unindo-se para a superação do fracasso escolar.

\section{REFERÊNCIAS}

BRASIL. Secretaria de Educação Continuada, Alfabetização, Diversidade e Inclusão. Política Nacional de Educação Especial na Perspectiva da Educação Inclusiva. Brasília: MEC/SECADI, 2013.

COLLARES, C. A. L. et al. Inteligência abstraída, crianças silenciadas: retomando o tema. In:VIOTTO FILHO, I. A. T; PONCE, R. F. Psicologia e pedagogia: perspectivas críticas para a ação psicopedagógica. Birigui: Boreal, 2012. p.80.

\section{CONSELHO FEDERAL DE PSICOLOGIA.} Referências técnicas para atuação de PSICÓLOGAS (OS) na educação básica. Brasília: Conselho Federal de Psicologia, 2013.

FACCI, M. G. D. A intervenção do psicólogo na formação de professores: contribuições da psicologia histórico-cultural. Campinas, SP: Alínea, 2009.

PATTO, M. H. S. A produção do fracasso escolar: histórias de submissão e rebeldia. São Paulo: [s.n.], 1984.

SAVIANI, D.; DUARTE, N. Pedagogia Históricocrítica e luta de classes na educação escolar. Campinas: Autores Associados, 2012.

SOUZA. M. P. R. Psicologia Escolar e políticas públicas em Educação: desafios contemporâneos. Em Aberto, Brasília, v. 23, n. 83, p. 129-149, 2010.

SOUZA. M. P. R.Psicologia Escolar e Educacional em busca de novas perspectivas. Revista Semestral da Associação Brasileira de Psicologia Escolar e Educacional, v. 13, n. 1, p. 179-182, jan./jun. 2009. https://doi.org/10.1590/S1413$\underline{85572009000100021}$

TANAMACHI, E. R. Visão crítica de educação e de psicologia: elementos para a construção de uma visão crítica de Psicologia Escolar. 1997. Tese (Doutorado) - Universidade Estadual Paulista, Marilia, 1997.
TULESKI, S. C.; EIDT, N. M. Repensando os distúrbios de aprendizagem a partir da psicologia histórico-cultural. Psicologia em Estudo, Maringá, v. 12 , n. 3, set./dez., 2007, p. 531-540. https://doi.org/10.1590/S141373722007000300010

Recebido para publicação em: 20/04/2016 Revisado em: 23/04/2016

Aceito em: 26/04/2016 